\title{
Molecular and Morphological Characterization of Colletotrichum Species in the Colletotrichum gloeosporioides Complex Associated with Persimmon Anthracnose in South Korea
}

Oliul Hassan, Jong Yeob Jeon, Taehyun Chang, ${ }^{\dagger}$ Jun Sung Shin, and Nam Kwon Oh, School of Ecology and Environmental System, College of Ecology \& Environmental Sciences, Kyungpook National University, Sangju, Gyeongsangbuk-do, 37224, Korea (Republic of); and Yong Se Lee, Division of Life and Environmental Sciences, College of Life and Environmental Sciences, Daegu University, Gyeongsan, Gyeongsangbuk-do, 38453, Korea (Republic of)

\begin{abstract}
Anthracnose is a major disease of persimmon in the pre- and postharvest phase. Several species of Colletotrichum (Colletotrichum gloeosporioides, C. acutatum, and C. horii) have been reported as causal agents of persimmon anthracnose in South Korea. In this study, a collection of 50 isolates associated with persimmon anthracnose were collected from Sangju $(n=25)$ and Cheongdo-gun $(n=25)$, South Korea. The morphological characteristics of all 50 Colletotrichum isolates were similar, and it was difficult to identify the isolates to the species level. A subsample of eight isolates was characterized phylogenetically to ascertain species. BLAST search and phylogenetic analysis of the internal transcribed spacer (ITS), glyceraldehyde-3-phosphate dehydrogenase

(GAPDH), and actin (ACT) genes revealed two species: $C$. horii as well as a previously unreported persimmon anthracnose causal agent C. siamense. C. siamense isolates were confirmed again by phylogenetic analysis of the ITS, ACT, GAPDH, calmodulin, and Apn2Mat1-2 intergenic spacer partial mating type genes. Koch's postulates for $C$. horii and $C$. siamense were fulfilled, confirming the pathogenicity of the two species in persimmon fruit. Morphological characteristics (colony morphology and size and shape of conidia and appressoria) from two representative isolates support results of the phylogenetic analysis and match those of previous descriptions of $C$. horii and C. siamense.
\end{abstract}

Persimmon (Diospyros kaki L. f.) is one of the popular fruit in the world. Persimmon fruit are believed to originate from Far East Asia (Badenes et al. 2003). Ancient records indicate that the domestication of D. kaki may have begun as early as 450 BCE (Luo and Wang 2008). The largest producers of persimmon fruit are China, Korea, Japan, Vietnam, Nepal, Brazil, Italy, Israel, and Spain. According to records from the Food and Agriculture Organization, China, Korea, and Japan produced 4,472,527 tons of persimmon fruit in 2014, which is approximately $95 \%$ of the total production worldwide. South Korea is the second most abundant producer of persimmon fruit in the world, providing approximately $10 \%$ of the world's fruit (FAO 2014).

In South Korea, as in other countries of the world, persimmon anthracnose is a serious disease, causing significant losses in yield and a reduction in fruit marketability. A single host plant can be infected by multiple Colletotrichum spp. (Huang et al. 2013; Y. C. Wang et al. 2016). Colletotrichum spp. responsible for persimmon anthracnose disease include Colletotrichum gloeosporioides, C. acutatum, and C. horii in Korea (Kwon and Kim 2011; Kwon et al. 2013); C. gloeosporioides, C. horii, and C. karstii in China (J. Wang et al. 2016; Xie et al. 2010; Zhang 2008); C. acutatum in the United States (Williamson and Sutton 2010); C. gloeosporioides in Spain (Palou et al. 2015); and C. gloeosporioides and $C$. horii in Brazil (May De Mio et. al. 2015). C. gloeosporioides is a very common cause of anthracnose disease in all persimmongrowing countries. C. gloeosporioides is also responsible for anthracnose disease in others plant species, including peach, blueberry, strawberry, almond, avocado, apple, and citrus plants (Hu et al. 2015). C. gloeosporioides is a complex consisting of 22 species plus one subspecies and includes C. asianum, C. cordylinicola, C. fructicola, C. gloeosporioides, C. horii, C. kahawae subsp. kahawae, C. musae, C. nupharicola, C. psidii, C. siamense, C. theobromicola, C. tropicale,

${ }^{\dagger}$ Corresponding author: T. Chang; E-mail: thchang@knu.ac.kr

O. Hassan and J. Y. Jeon contributed equally to this work.

Accepted for publication 11 December 2017.

C) 2018 The American Phytopathological Society
C.xanthorrhoeae, C. aenigma, C. aeschynomenes, C. alatae, C. alienum, C. aotearoa, C. clidemiae, C. kahawae subsp. ciggaro, C. salsolae, and $C$. ti, plus nom. nov. C. queenslandicum (Weir et al. 2012). It is very difficult to separate these species $(C$. gloeosporioides is a species complex) based on a few distinguishing morphological characteristics. Colony colors and growth rate, conidia size, and shape of appressoria are some of the characteristics used to distinguish species of Colletotrichum (Hu et al. 2015; Hyde et al. 2009). However, these criteria alone are not sufficient to identify Colletotrichum spp. because of variations in the phenotypes of species under different environmental conditions (Hyde et al. 2009; Weir et al. 2012). Many Colletotrichum spp. were synonymized with the name of $C$. gloeosporioides because of the round ends and cylindrical conidia (Phoulivong et al. 2010). Later, several synonymized $C$. gloeosporioides species were identified as members of the $C$. acutatum and $C$. boninense species complexes (Damm et al. 2012a,b).

The available DNA (various genomic regions) sequences of $\mathrm{Col}$ letotrichum spp. have become increasingly important for identification. Colletotrichum spp. can be identified by comparing DNA sequences of isolates, which overcomes the limitations of morphological identification (Cai et al. 2009). Most Colletotrichum spp. were identified based on sequences of the nuclear ribosomal internal transcribed spacer (ITS) region or a combination of ITS and TUB2 sequences, which have been shown to be insufficient to fully differentiate Colletotrichum spp. (Diao et al. 2017; Liu et al. 2016). Multilocus molecular characteristics are also broadly applied for the identification of Colletotrichum spp.

Despite several reports of persimmon anthracnose caused by Colletotrichum spp. in South Korea, the C. gloeosporioides species complex has not yet been identified among fungal isolates from persimmon. Therefore, our research objectives were to characterize C. gloeosporioides isolates from the main persimmon-growing area in South Korea by molecular and morphological analyses. The pathogenicity of different Colletotrichum spp. on persimmon fruit was also assessed.

\section{Materials and Methods}

Collection of diseased persimmon fruit. Sampling sites for this study were 10 farmers' fields, with 5 in Sangju and 5 in Cheongdo-gun in South Korea. In total, 50 diseased persimmon fruit, with 5 fruit 
showing anthracnose disease symptoms (Fig. 1A and B), were collected from each field and brought to the laboratory. Diseased fruit were cleaned under running tap water to remove foreign material and then stored in sterile polythene bags until further use.

Isolation of causal agents. The presumed causal agents of anthracnose disease were isolated from necrotic tissue of the diseased fruit. Before the isolation process, diseased fruit were surface disinfected in $95 \%$ ethanol and washed in distilled water. A small piece of necrotic tissue $\left(1 \mathrm{~cm}^{2}\right)$ was cut from the inside of a lesion on each fruit, surfaces were disinfected with $0.5 \%$ sodium hypochlorite solution for $2 \mathrm{~min}$, and the pieces were washed thrice in sterile distilled water to remove the sterilizing agent, dried by blotting, and then placed on water agar containing streptomycin $(0.05 \mathrm{~g} / \mathrm{liter})$. Plates were incubated at $25^{\circ} \mathrm{C}$ until fungal hypha emerged from the necrotic tissue. After 2 to 3 days of incubation, individual hyphal tips were transferred to fresh potato dextrose agar (PDA). For pure cultures, isolates were hyphal tipped twice, and 50 isolates were collected and grouped (four groups) based on morphological observations. Eight isolates, with an equal number representing each group, were selected for phylogenetic and morphological analyses. For long-term storage, three to four plugs ( $5 \mathrm{~mm}$ in diameter from the mycelium) of fungal colonies of each isolate were placed in a tube containing sterile aqueous solution of $20 \%$ glycerol and stored at $-20^{\circ} \mathrm{C}$.

Genomic DNA extraction, polymerase chain reaction, and sequencing. Total genomic DNA of all representative isolates selected for phylogenetic analysis was extracted using a HiGene Genomic DNA Prep Kit (Yuseong-Gu) following the manufacturer's instructions. Fungal colonies, 3 to 4 days old and grown at $25^{\circ} \mathrm{C}$ in the dark on PDA, were used to extract genomic DNA. Preliminary analysis of the isolates used partial gene sequences of three genomic loci:
ITS, glyceraldehyde-3-phosphate dehydrogenase (GAPDH), and actin (ACT) genes. Four isolates were confirmed to be $C$. horii and four isolates were preliminarily identified as $C$. siamense. Four $C$. siamense isolates were further analyzed using partial gene sequences of five genomic loci: ITS, ACT, GAPDH, Apn2-Mat1-2 intergenic spacer partial mating type (Mat1-2) (ApMat), and calmodulin (CAL) genes. The primer pairs ITS-1F/ITS4, GDF/GDR, ACT512F/ACT-783R, CL1C/CL2C, and AMF1/AMR1 were used to amplify and sequence the ITS (ITS1-5.8S-ITS2) region, GAPDH, ACT, CAL, and ApMat genes, respectively, from the genomic DNA (Carbone and Kohn 1999; Silva et al. 2012; Templeton et al. 1992; Weir et al. 2012; White et al. 1990). All primers used in this study and their sequences are listed in Table 1 . All polymerase chain reactions (PCR) were performed using a SimpliAmp thermal cycler (Thermo Fisher Scientific Inc.). The 25- $\mu$ l PCR mixture contained $2.5 \mu \mathrm{l}$ of $10 \times$ Ex Taq buffer, $0.5 \mu \mathrm{l}$ of dNTP mix, $1 \mu l$ of forward primer $(10 \mathrm{pmol}), 1 \mu \mathrm{l}$ of reverse primer $(10 \mathrm{pmol}), 1 \mu \mathrm{l}$ of genomic DNA, $0.4 \mu$ l of Taq DNA polymerase, and $18.2 \mu$ l of sterilized water (BIOFACT). PCR for the ITS region was programmed with an initial denaturation at $95^{\circ} \mathrm{C}$ for $4 \mathrm{~min}$; followed by 34 cycles of $95^{\circ} \mathrm{C}$ for 30 $\mathrm{s}$, annealing at $52^{\circ} \mathrm{C}$ for $30 \mathrm{~s}$, and extension at $72^{\circ} \mathrm{C}$ for $45 \mathrm{~s}$; and a final elongation at $72^{\circ} \mathrm{C}$ for $7 \mathrm{~min}$. For genes, the PCR program was largely identical with that used for ITS amplification, except for annealing temperatures. The annealing temperatures were adjusted to 55, 58, 59, and $62^{\circ} \mathrm{C}$ for GAPDH, ACT, CAL, and ApMat, respectively. The PCR products were electrophoresed in $1 \%$ agarose gels at $130 \mathrm{~V}$ for $25 \mathrm{~min}$ in $1 \times$ Tris-borate-EDTA buffer to confirm the success of the reactions and then purified using a HiGene PCR Purification Kit (Yuseong-Gu). Both strands of the amplified DNA were sequenced directly with the help of Macrogen, Inc.
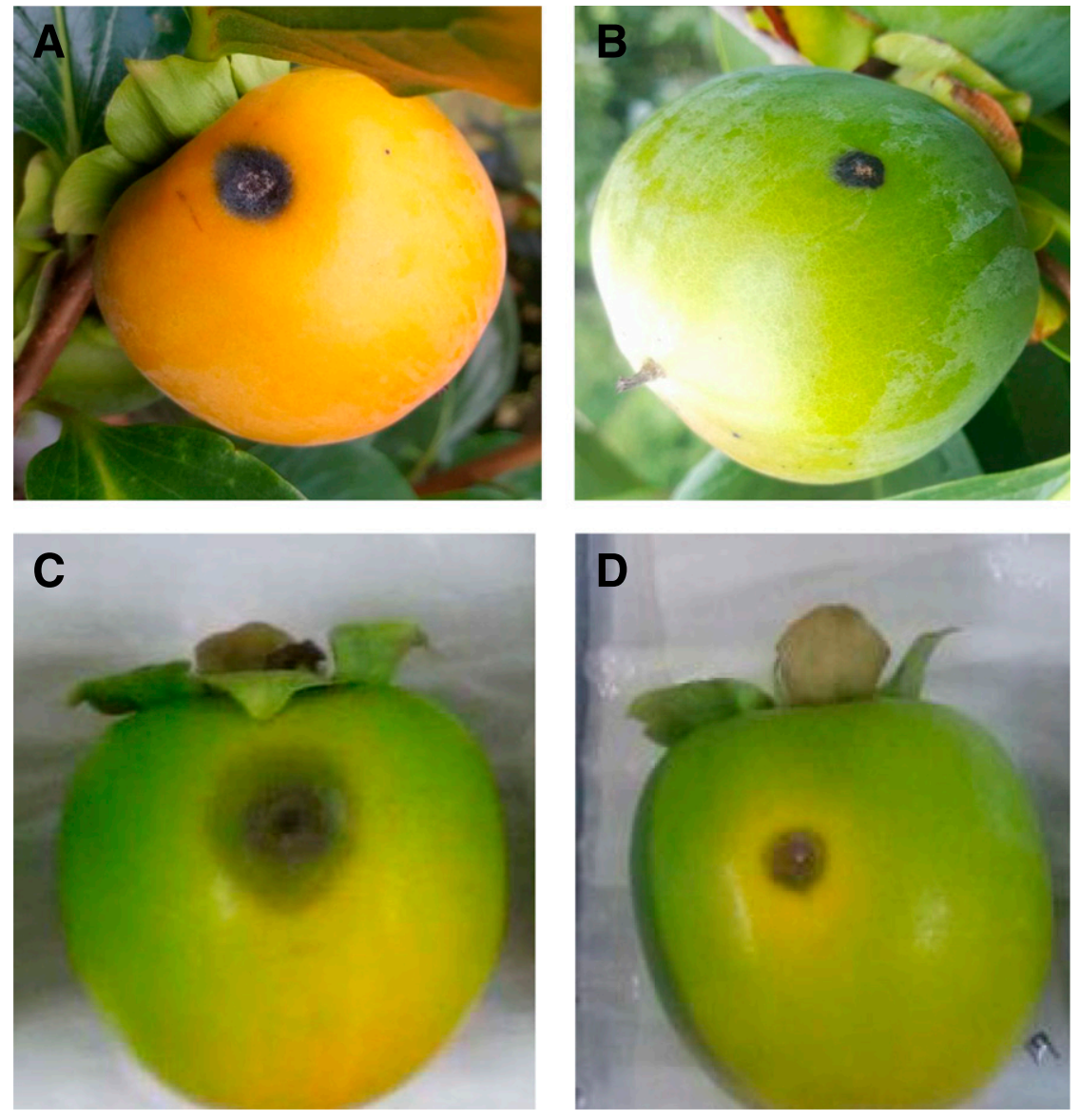

Fig. 1. Diseased persimmon fruit showing typical anthracnose disease symptoms. A and B, Symptoms caused by Colletotrichum spp. on fruit in infected fruit. C, Lesions generated by Colletotrichum siamense in detached persimmon fruit at 10 days after inoculation (wounding method). D, Lesions generated by C. horii in detached persimmon fruit at 10 days after inoculation (wounding method). 
Phylogenetic analysis. The sequences of the ITS region and GAPDH and ACT genes of the present isolates were compared with Colletotrichum spp. sequences previously deposited in GenBank (https://blast.ncbi.nlm.nih.gov/). Multiple sequence alignments were performed using the Clustal Omega multiple sequence alignment program of MEGA, version 6.0 (Tamura et al. 2013). The ITS, GAPDH, and ACT sequences of 24 taxa in the C. gloeosporioides species complex (Weir et al. 2012) were retrieved from GenBank as reference sequences (Table 2). Neighbor-joining (NJ) and maximum-parsimony (MP) trees were constructed using MEGA, version 6.0 (Tamura et al. 2013), based on a combined dataset of the ITS, GAPDH, and ACT sequences. The relative stability of the branches was evaluated by bootstrapping with 1,000 replications. Concatenated sequences of ITS, ACT, GAPDH, CAL, and ApMat genes from four $C$. siamense complexes with selected reference type strains in the Musae clade of the $C$. gloeosporioides species complex (Table 2) were generated (Weir et al. 2012). NJ phylogenetic analyses were performed using MEGA, version 6.0 (Tamura et al. 2013).

Morphological examination. From each species, two representative isolates of each species (C. siamense, isolates ICK-23 and ICK47; and $C$. horii, isolates ICK-103 and ICK-111) were selected for morphological characterization. To observe colony morphology and determine the mycelium growth rate, mycelial discs $(5 \mathrm{~mm}$ in diameter) were removed from the actively growing edge of 4-day-old cultures, and each mycelial disc was paced onto a 90-mm PDA plate. The plates were incubated at $25^{\circ} \mathrm{C}$ in the dark. Colony characteristics (color, size, and texture) were noted after 5 days, and colony diameter was recorded daily, with three replicate cultures of each isolate and two measurements per replicate. The average growth rate was calculated by determining the millimeter change per day. To better understand conidial and appressoria morphologies, we followed the slide culture technique. Square blocks of the medium $(10 \mathrm{by} 10 \mathrm{~mm})$ were cut from the PDA plate and aseptically transferred to the middle of a slide. Four sides of the agar square were inoculated with mycelial fragments of the same representative isolate using a sterile loop. Cover slips were placed on the inoculated agar samples, and then the slides were placed inside Petri dishes containing moist filter paper on a glass support. The slides were incubated at $25^{\circ} \mathrm{C}$ in the dark for 7 days. Conidia and appressoria formed across the underside of the cover slip, and their shapes and sizes were measured with a stage micrometer under an Olympus BX43 microscope (Olympus Corporation) at $\times 400$ magnification. For each isolate, at least 20 conidia and appressoria were measured. Analysis of variance $(P<0.05)$ and least significant different tests were conducted using the statistical software package JMP.

Pathogenicity test. Representative isolates of $C$. siamense and C. horii were tested for pathogenicity on mature and green persimmon fruit in the laboratory to confirm their ability to cause anthracnose disease. Persimmon fruit of similar stages and sizes were collected from persimmon orchards, thoroughly washed with tap water, and surface sterilized with $70 \%$ ethanol and $1 \% \mathrm{NaOCl}$. The disinfected fruit were then rinsed in sterile distilled water, and each fruit was placed in a small plastic saucer and allowed to dry before inoculation. Conidial suspensions were prepared from 5- to 7-day-old cultures in distilled water. The concentrations of spore suspensions were adjusted to $10^{5}$ conidia/ml using a hemocytometer. The sterilized fruit were inoculated with conidial suspension of each isolate by wounding methods. For the wounding method, persimmon fruit were wounded by pricking with a needle to about $5 \mathrm{~mm}$ in depth and placing a 10- $\mu$ ldroplet of conidial suspension over the wound. Distilled water was used as a negative control. The plastic saucers with the inoculated fruit (positive and negative controls) were transferred in a sterile plastic box containing moist tissue paper, the lid was fixed, and the cultures were incubated at $25^{\circ} \mathrm{C}$ and high humidity until the disease developed. Lesion diameter (LD) was measured with a ruler and disease incidence (DI) was expressed as the percentage of infected fruit with the total number of fruit inoculated. Five replicate fruit were tested per isolate and the experiment was performed twice. LD and DI data of the two independent experiments were combined because variance was homogenous. Then, LD and DI of the two species were compared using Duncan's multiplerange test $(\alpha=0.05)$ with the help of JMP Pro 10.0.0 software. The causal agents were reisolated on PDA and identified based on morphological and molecular analyses, as described above.

\section{Results}

Molecular identification. All of the isolates were identified based on the obtained ITS, ACT, and GAPDH sequences (Table 3). A BLAST search resulted in sequences from two Colletotrichum spp. of $>99 \%$ sequence similarity: $C$. siamense and $C$. horii (Table 3 ). The isolates ICK-3, ICK-22, ICK-23, and ICK-47 were identified as $C$. siamense and ICK-84, ICK-91, ICK-103, and ICK-111 as $C$. horii. Although the ITS sequences of ICK-3 and ICK-22 matched with undefined Colletotrichum spp. and ICK-47 matched with $C$. gloeosporioides. Their (ICK-3, ICK-22, ICK-23, and ICK-47) ACT and GAPDH gene sequence were most similar to those of $C$. siamense isolates (BMLI15, LQ22, Xt-18-1, and LC3049). Short descriptions of the isolates ICK-84, ICK-91, ICK-103, and ICK-111 as C. horii are available in our previous article (Jeon et al. 2017).

Phylogenetic analysis. A phylogenetic analysis was conducted using the NJ and MP methods (MEGA, version 6.0) to compare the ITS, ACT, and GAPDH nucleotide sequences from eight isolates obtained in this study and reference strains of the C. gloeosporioides complex (Table 2). The eight isolates clustered into two large groups in the MP phylogenetic tree (Fig. 2) with $99 \%$ bootstrap support. The isolates ICK-3, ICK-22, ICK-23, and ICK-47 formed a clade with C. siamense (reference strains ICMP 12567, ICMP 17795, ICMP 18118, and ICMP 18575) and reference strains of the Musae clade of the $C$. gloeosporioides complex. In this clade, only ICK-23 formed a distinct clade with strains ICMP 17795 and ICMP 18118 (C. siamense). The resulting topology of $\mathrm{NJ}$ analysis was largely identical to the topology of MP analysis (Fig. 3). For more clarification, a phylogenetic tree was constructed based on the combined nucleotide sequences of ITS, ACT, GAPDH, CAL, and ApMat from ICK-3, ICK-22, ICK-23, and ICK-47 and reference strains in the Musae clade of the $C$. gloeosporioides complex, including $C$. siamense (Fig. 4). In this tree, isolates ICK-3, ICK-22, ICK-23, and ICK-47

Table 1. Primers used in this study, with sequences and sources

\begin{tabular}{lllll}
\hline Gene $^{\mathbf{z}}$ & Primer name & Direction & \multicolumn{1}{c}{ Sequence $\mathbf{( 5 ^ { \prime } - \mathbf { 3 } ^ { \prime } )}$} & \multicolumn{1}{c}{ References } \\
\hline GAPDH & GDF & Forward & GCC GTC AAC GAC CCC TTC ATT GA & Templeton et al. 1992 \\
& GDR & Reverse & GGG TGG AGT CGT ACT TGA GCA TGT & Templeton et al. 1992 \\
ITS & ITS-1F & Forward & CTT GGT CAT TTA GAG GAA GTA A & White et al. 1990 \\
& ITS-4 & Reverse & TCC TCC GCT TAT TGA TAT GC & White et al. 1990 \\
CAL & CL1C & Forward & GAA TTC AAG GAG GCC TTC TC & Weir et al. 2012 \\
& CL2C & Reverse & CTT CTG CAT CAT GAG CTG GAC & Weir et al. 2012 \\
Actin & ACT-512F & Forward & ATG TGC AAG GCC GGT TTC GC & Carbone and Kohn 1999 \\
& ACT-783R & Reverse & TAC GAG TCC TTC TGG CCC AT & Carbone and Kohn 1999 \\
ApMat & AM-F & Forward & TCATTCTACGTATGTGCCCG & Silva et al. 2012 \\
& AM-R & Reverse & CCAGAAATACACCGACTTGC & Silva et al. 2012 \\
\hline
\end{tabular}

${ }^{\mathrm{z}}$ GAPDH = glyceraldehyde-3-phosphate dehydrogenase, ITS = internal transcribed spacer, CAL = calmodulin, and ApMat = Apn2-Mat1-2 intergenic spacer partial mating type. 
Table 2. GenBank accession numbers of Colletotrichum isolates used in this study for molecular data analyses

\begin{tabular}{|c|c|c|c|c|c|c|c|}
\hline \multirow[b]{2}{*}{ Species, isolate ${ }^{\mathrm{z}}$} & \multirow[b]{2}{*}{ Origin } & \multirow[b]{2}{*}{ Source } & \multicolumn{5}{|c|}{ GenBank accession number ${ }^{y}$} \\
\hline & & & GAPDH & ITS & ACT & CAL & ApMat \\
\hline \multicolumn{8}{|c|}{ Colletotrichum siamense } \\
\hline ICK-3 & Korea & This study & LC260529 & LC260488 & LC260525 & LC260532 & LC307171 \\
\hline ICK-22 & Korea & This study & LC260530 & LC260489 & LC260526 & LC260533 & LC307172 \\
\hline ICK-23 & Korea & This study & LC260531 & LC260490 & LC260527 & LC260534 & LC307173 \\
\hline ICK-47 & Korea & This study & LC208834 & LC208833 & LC260528 & LC208835 & LC307174 \\
\hline ICMP17795 & United States & GenBank & JX010051 & JX010162 & JX009506 & JX009703 & $\ldots$ \\
\hline ICMP 12567 & Australia & GenBank & JX009940 & JX010250 & JX009541 & JX009697 & $\ldots$ \\
\hline ICMP18118 & Nigeria & GenBank & JX009941 & JX010163 & JX009505 & JX009701 & $\ldots$ \\
\hline ICMP 18575 & Thailand & GenBank & JX010059 & JX010256 & JX009455 & JX009717 & $\ldots$ \\
\hline ICMP 18578* & Thailand & GenBank & JX009924 & $\ldots$ & FJ907423 & FJ917505 & JQ899289 \\
\hline \multicolumn{8}{|c|}{ syn. C. jasminisambac } \\
\hline ICMP19118 & Vietnam & GenBank & HM131497 & $\ldots$ & HM131507 & JX009713 & JQ807841 \\
\hline \multicolumn{8}{|c|}{ syn. C. hymenocallidis } \\
\hline ICMP18642 & China & GenBank & JX010019 & $\ldots$ & GQ856775 & JX009709 & JQ899283 \\
\hline \multicolumn{8}{|l|}{ C. horii } \\
\hline ICK-84 & Korea & This study & LC186036 & LC186040 & LC186032 & $\ldots$ & $\ldots$ \\
\hline ICK-91 & Korea & This study & LC186035 & LC186039 & LC186031 & $\ldots$ & $\ldots$ \\
\hline ICK-103 & Korea & This study & LC186038 & LC186042 & LC186034 & $\cdots$ & $\cdots$ \\
\hline ICK-111 & Korea & This study & LC186037 & LC186041 & LC186033 & $\ldots$ & $\ldots$ \\
\hline ICMP 12942 & New Zealand & GenBank & GQ329685 & GQ329687 & JX009533 & $\ldots$ & $\ldots$ \\
\hline ICMP12951 & New Zealand & GenBank & GQ329683 & GQ329689 & JX009466 & $\ldots$ & $\ldots$ \\
\hline ICMP 17968 & China & GenBank & GQ329682 & JX010212 & JX009547 & $\ldots$ & $\ldots$ \\
\hline ICMP 17970 & Japan & GenBank & GQ329686 & JX010213 & JX009467 & $\ldots$ & $\ldots$ \\
\hline \multicolumn{8}{|l|}{ C. aenigma } \\
\hline ICMP 18686 & Japan & GenBank & JX009913 & JX010243 & JX009519 & JX009684 & $\ldots$ \\
\hline ICMP 18608* & Israel & GenBank & JX010044 & $\ldots$ & JX009443 & JX009683 & KM360143 \\
\hline \multicolumn{8}{|l|}{ C. aeschynomenes } \\
\hline ICMP $17673^{*}$ & United States & GenBank & JX009930 & JX010176 & JX009483 & JX009721 & KM360145 \\
\hline \multicolumn{8}{|l|}{ C. alatae } \\
\hline ICMP 17919* & India & GenBank & JX009990 & JX010190 & JX009471 & JX009738 & KC888932 \\
\hline \multicolumn{8}{|l|}{ C. alienum } \\
\hline ICMP 18703 & New Zealand & GenBank & JX010030 & JX010252 & JX009528 & JX009656 & $\ldots$ \\
\hline ICMP 12071* & New Zealand & GenBank & JX010018 & $\ldots$ & JX009580 & JX009654 & KM360144 \\
\hline \multicolumn{8}{|l|}{ C. aotearoa } \\
\hline ICMP 18532 & New Zealand & GenBank & JX009906 & JX010220 & JX009544 & $\ldots$ & $\ldots$ \\
\hline \multicolumn{8}{|l|}{ C. asianum } \\
\hline ICMP 18696 & Australia & GenBank & JX009915 & JX010192 & JX009576 & JX009723 & $\ldots$ \\
\hline \multirow[t]{2}{*}{ ICMP $18580^{*}$} & Thailand & GenBank & JX009915 & $\ldots$ & JX009576 & FJ917506 & FR718814 \\
\hline & & & & & & \multicolumn{2}{|c|}{ (Continued on next page) } \\
\hline
\end{tabular}

formed a distinct clade with $C$. siamense from other strains in the Musae clade with high bootstrap support (80\%). The isolates ICK84, ICK-91, ICK-103, and ICK-111 formed a distinct clade with C. horii (reference strains ICMP 12942, ICMP 12951, ICMP 17968, and ICMP 17970), with reference strains from both the Musae and Kahawae clades and with a posterior probability of 99\% (Fig. 2).

Morphological characterization of the Colletotrichum spp. isolates obtained in the present study. Morphological characteristics of two Colletotrichum spp. are given below in detail.

Isolates ICK-23 and ICK-47 (C. siamense). Fast-growing colonies of $C$. siamense on PDA were white to off-white, with dense whitish mycelia. The reverse color was creamy yellow to dull yellow toward the center, with a yellowish conidial mass across the colony (Fig. 5A and B). The mycelium growth rate was 7.20 to $8.77 \mathrm{~mm} /$ day, with a mean of $8.35 \mathrm{~mm} /$ day at $25^{\circ} \mathrm{C}$ on PDA. Single-celled conidia were observed across the colony. The conidia were cylindric, straight, nonseptate, and fusiform, with obtuse ends and guttulate (Fig. 5C). The size of conidia ranged from 12.0 to $18.6 \mu \mathrm{m}$ (mean $15 \mu \mathrm{m}$ ) long and 3.5 to $6.1 \mu \mathrm{m}$ (mean $5 \mu \mathrm{m}$ ) wide (Fig. 5C). Brown-colored appressoria, observed in 2-day-old slide cultures, were globose, with a few clavate, but became complex with irregular lobes after 7 days of incubation. The sizes of the appressoria were 11.4 to $19.1 \times 5.2 \times$
$9.1 \mu \mathrm{m}$ (mean: $14.2 \times 7.3 \mu \mathrm{m})$ (Fig. 5D and E). There were no clear differences in morphological characteristics between the $C$. siamense isolates tested in this study.

Isolate ICK-103 and ICK-111 (C. horii). Colonies of C. horii isolates were cottony and were initially white and then became grayish as the cultures aged on PDA, with dark concentric zonation and regular margins in reverse (Fig. 5A and B). The mycelium growth rate ranged 6.96 to $8.14 \mathrm{~mm} /$ day (mean: $7.51 \mathrm{~mm}$ ) at $25^{\circ} \mathrm{C}$ on PDA. Few conidia (no conidial mass) were observed across the colony after 14 days of incubation at $25^{\circ} \mathrm{C}$ on PDA. Conidia were hyaline, onecelled, cylindrical, straight, a few slightly curved, obtuse apices, tapering toward the base and measuring up to 14.5 to $20.8 \times 4.0$ to $5.78 \mu \mathrm{m}$ (mean: $17 \times 4.5 \mu \mathrm{m})($ Fig. $6 \mathrm{C}$ ). Appressoria, arising from vegetative hyphae, were observed on the sterile covers slips. They were short, cylindric, light brown to brown, smooth, and mostly uniform in outline, with a few irregularly lobed (Fig. 6D and E). The sizes of the appressoria were 9.5 to $13.8 \times 5.5$ to $8.4 \mu \mathrm{m}$ (mean: $11.1 \times 7 \mu \mathrm{m})$ (Fig. $6 \mathrm{D}$ and E). The morphological characteristics of both isolates tested in this study were similar.

Pathogenicity of $\boldsymbol{C}$. siamense and $\boldsymbol{C}$. horii. All tested Colletotrichum isolates caused anthracnose lesions on detached persimmon fruit inoculated by the wounding method (Fig. 1D and C). No lesions developed on fruit inoculated with water. $C$. siamense isolates 
Table 2. (Continued from previous page)

\begin{tabular}{|c|c|c|c|c|c|c|c|}
\hline \multirow[b]{2}{*}{ Species, isolate ${ }^{z}$} & \multirow[b]{2}{*}{ Origin } & \multirow[b]{2}{*}{ Source } & \multicolumn{5}{|c|}{ GenBank accession number ${ }^{y}$} \\
\hline & & & GAPDH & ITS & ACT & CAL & ApMat \\
\hline \multicolumn{8}{|l|}{ C. boninense } \\
\hline ICMP 17904 & Japan & GenBank & JX009905 & JX010292 & JX009827 & $\ldots$ & $\ldots$ \\
\hline \multicolumn{8}{|l|}{ C. clidemiae } \\
\hline ICMP 18706 & United States & GenBank & JX009909 & JX010274 & JX00947 & $\ldots$ & $\ldots$ \\
\hline \multicolumn{8}{|l|}{ C. cordylinicola } \\
\hline ICMP 18579 & Thailand & GenBank & JX009975 & JX010226 & HM470235 & $\ldots$ & $\ldots$ \\
\hline \multicolumn{8}{|l|}{ C. fructicola } \\
\hline ICMP 12568 & Australia & GenBank & JX009946 & JX010166 & JX009529 & JX009680 & $\ldots$ \\
\hline ICMP $18581^{*}$ & Thailand & GenBank & JX010033 & $\ldots$ & FJ907426 & FJ917508 & JQ807838 \\
\hline \multicolumn{8}{|l|}{ C. gloeosporioides } \\
\hline ICMP 18738 & Australia & GenBank & JX009976 & JX010151 & JX009542 & JX009730 & $\ldots$ \\
\hline ICMP $17821 *$ & Italy & GenBank & JX010054 & $\ldots$ & JX009558 & JX009731 & JQ807843 \\
\hline \multicolumn{8}{|l|}{ C. hippeastri } \\
\hline ICMP 17920 & The Netherlands & GenBank & JX009932 & JX010293 & JX009485 & $\ldots$ & $\ldots$ \\
\hline \multicolumn{8}{|c|}{ C. kahawae subsp. ciggaro } \\
\hline ICMP 18728 & Brazil & GenBank & JX010048 & JX010239 & JX009525 & $\ldots$ & $\ldots$ \\
\hline \multicolumn{8}{|l|}{ C. musae } \\
\hline ICMP 12931 & New Zealand & GenBank & JX009995 & JX010140 & JX009442 & JX009688 & $\ldots$ \\
\hline ICMP 19119* & United States & GenBank & JX010050 & $\ldots$ & JX009433 & JX009742 & KC888926 \\
\hline \multicolumn{8}{|l|}{ C. nupharicola } \\
\hline ICMP 17938 & United States & GenBank & JX009936 & JX010189 & JX009486 & JX009661 & $\ldots$ \\
\hline ICMP 18658* & United States & GenBank & JX009972 & $\ldots$ & JX009437 & JX009663 & JX145319 \\
\hline \multicolumn{8}{|l|}{ C. psidii } \\
\hline ICMP 19120 & Italy & GenBank & JX009967 & JX010219 & JX009515 & $\ldots$ & $\ldots$ \\
\hline \multicolumn{8}{|l|}{ C. queenslandicum } \\
\hline ICMP 1780 & Australia & GenBank & JX010010 & JX010186 & JX009504 & JX009693 & $\ldots$ \\
\hline ICMP1778* & Australia & GenBank & JX009934 & $\ldots$ & JX009447 & JX009691 & KC888928 \\
\hline \multicolumn{8}{|l|}{ C. salsolae } \\
\hline ICMP $19051 *$ & Hungary & GenBank & JX009916 & JX010242 & JX009562 & JX009696 & KC888925 \\
\hline \multicolumn{8}{|l|}{ C. theobromicola } \\
\hline ICMP 18566 & Australia & GenBank & JX009953 & JX010282 & JX009496 & $\ldots$ & $\ldots$ \\
\hline \multicolumn{8}{|l|}{ C. $t i$} \\
\hline ICMP 4832 & New Zealand & GenBank & JX009952 & JX010269 & JX009520 & $\ldots$ & $\ldots$ \\
\hline \multicolumn{8}{|l|}{ C. tropicale } \\
\hline ICMP 18672 & Japan & GenBank & JX010020 & JX010275 & JX009480 & JX009722 & $\ldots$ \\
\hline ICMP $18653^{*}$ & Panama & GenBank & JX010007 & & JX009489 & JX009719 & KC790728 \\
\hline \multicolumn{8}{|l|}{ C. xanthorrhoeae } \\
\hline ICMP 17903 & Australia & GenBank & JX009927 & JX010261. & JX009478 & $\ldots$ & $\ldots$ \\
\hline
\end{tabular}

Table 3. Closest relatives of Colletotrichum spp. isolated from Diospyros kaki L. based on a BLAST search analyses of internal transcribed spacer (ITS), actin, and glyceraldehyde-3-phosphate dehydrogenase (GAPDH) gene sequences

\begin{tabular}{|c|c|c|c|}
\hline \multirow[b]{2}{*}{ Isolate } & \multicolumn{3}{|c|}{ Closest organism in GenBank (accession number) based on } \\
\hline & Resulting ITS sequences & Resulting actin sequences & Resulting GAPDH sequences \\
\hline \multirow[t]{2}{*}{ ICK 3} & $\begin{array}{l}\text { Uncultured Colletotrichum C203O7 } \\
\text { (KF718216) }\end{array}$ & C. siamense BMLI15 (FJ907422) & C. siamense $\mathrm{Xt}-18-1$ (KM053171) \\
\hline & Similarity: $100 \%$ & Similarity: $100 \%$ & Similarity: $100 \%$ \\
\hline \multirow[t]{2}{*}{ ICK 22} & $\begin{array}{l}\text { Uncultured Colletotrichum C203O7 } \\
\text { (KF718216) }\end{array}$ & C. siamense LQ22 (KX885157) & C. siamense LC3049 (KP703305) \\
\hline & Similarity: $99 \%$ & Similarity: $100 \%$ & Similarity: $100 \%$ \\
\hline \multirow[t]{2}{*}{ ICK 23} & C. siamense Cg363 (KX513879) & C. siamense LQ22 (KX885157) & C. siamense $\mathrm{Xt}-18-1(\mathrm{KM} 053171)$ \\
\hline & Similarity: $100 \%$ & Similarity: $100 \%$ & Similarity: $100 \%$ \\
\hline \multirow[t]{2}{*}{ ICK 47} & C. gloeosporioides 16-412(LC194223) & C. siamense LQ22 (KX885157) & C. siamense $\mathrm{Xt}-18-1(\mathrm{KM} 053171)$ \\
\hline & Similarity: $99 \%$ & Similarity: $100 \%$ & Similarity: $100 \%$ \\
\hline ICK 84 & $\begin{array}{l}\text { C. horii OGaC1 (KU239182) } \\
\text { Similarity: } 100 \%\end{array}$ & $\begin{array}{l}\text { C. horii CPC } 20992 \text { (KC566947) } \\
\text { Similarity: } 100 \%\end{array}$ & $\begin{array}{l}\text { C. horii C1069 (JX010001) } \\
\text { Similarity. } 100 \%\end{array}$ \\
\hline ICK 91 & $\begin{array}{l}\text { C. horii OGaC1 (KU239182) } \\
\text { Similarity: } 100 \%\end{array}$ & $\begin{array}{l}\text { C. horii CPC } 20992 \text { (KC566947) } \\
\text { Similarity: } 100 \%\end{array}$ & $\begin{array}{l}\text { C. horii C1069 (JX010001) } \\
\text { Similarity: } 100 \%\end{array}$ \\
\hline ICK 103 & $\begin{array}{l}\text { C. horii OGaC1 (KU239182) } \\
\text { Similarity: } 100 \%\end{array}$ & $\begin{array}{l}\text { C. horii CPC } 20992 \text { (KC566947) } \\
\text { Similarity: } 100 \%\end{array}$ & $\begin{array}{l}\text { C. horii C1069 (JX010001) } \\
\text { Similarity: } 100 \%\end{array}$ \\
\hline ICK 111 & $\begin{array}{l}\text { C. horii } \mathrm{OGaC} 1 \text { (KU239182) } \\
\text { Similarity: } 100 \%\end{array}$ & $\begin{array}{l}\text { C. horii CPC } 20992 \text { (KC566947) } \\
\text { Similarity: } 100 \%\end{array}$ & $\begin{array}{l}\text { C. horii C1069 (JX010001) } \\
\text { Similarity: } 100 \%\end{array}$ \\
\hline
\end{tabular}


produced significantly larger lesions than those of $C$. horii isolates in inoculated fruit. LD of $C$. siamense were 17.26 to $22.85 \mathrm{~mm}$, with mean of $19.80 \pm 0.71 \mathrm{~mm}$, whereas the LD of $C$. horii were 6.94 to $9.87 \mathrm{~mm}$, with mean of $7.90 \pm 0.52 \mathrm{~mm}$. DI of both Colletotrichum spp. isolates were $100 \%$ (Table 4). Confirmation of pathogenicity was fulfilled by reisolating these species from the inoculated persimmon fruit. Conidia shape, size, and colony morphologies were identical to the originals, and the isolates were reidentified to the species level.

\section{Discussion}

Based on perceived scientific and economic importance, the genus Colletotrichum is considered the eighth most important group of plant-pathogenic fungi in the world (Cannon et al. 2012; Dean et al. 2012). C. gloeosporioides, responsible for anthracnose on herbaceous and woody plants, is one of the most destructive species of Colletotrichum (over 700 species) (Dean et al. 2012). Persimmon anthracnose caused by Colletotrichum spp. has become increasingly common in South Korea. The main objectives of this study were to identify Colletotrichum isolates associated with persimmon anthracnose in key persimmon-growing areas of South Korea to the species level, based on morphology and a multigene phylogenetic analysis.

Colletotrichum spp. associated with persimmon anthracnose in Sangju and Cheongdo-gun, South Korea, were determined based on their phylogenetic affinities and pathogenicities. C. siamense and $C$. horii, which belong to the $C$. gloeosporioides species

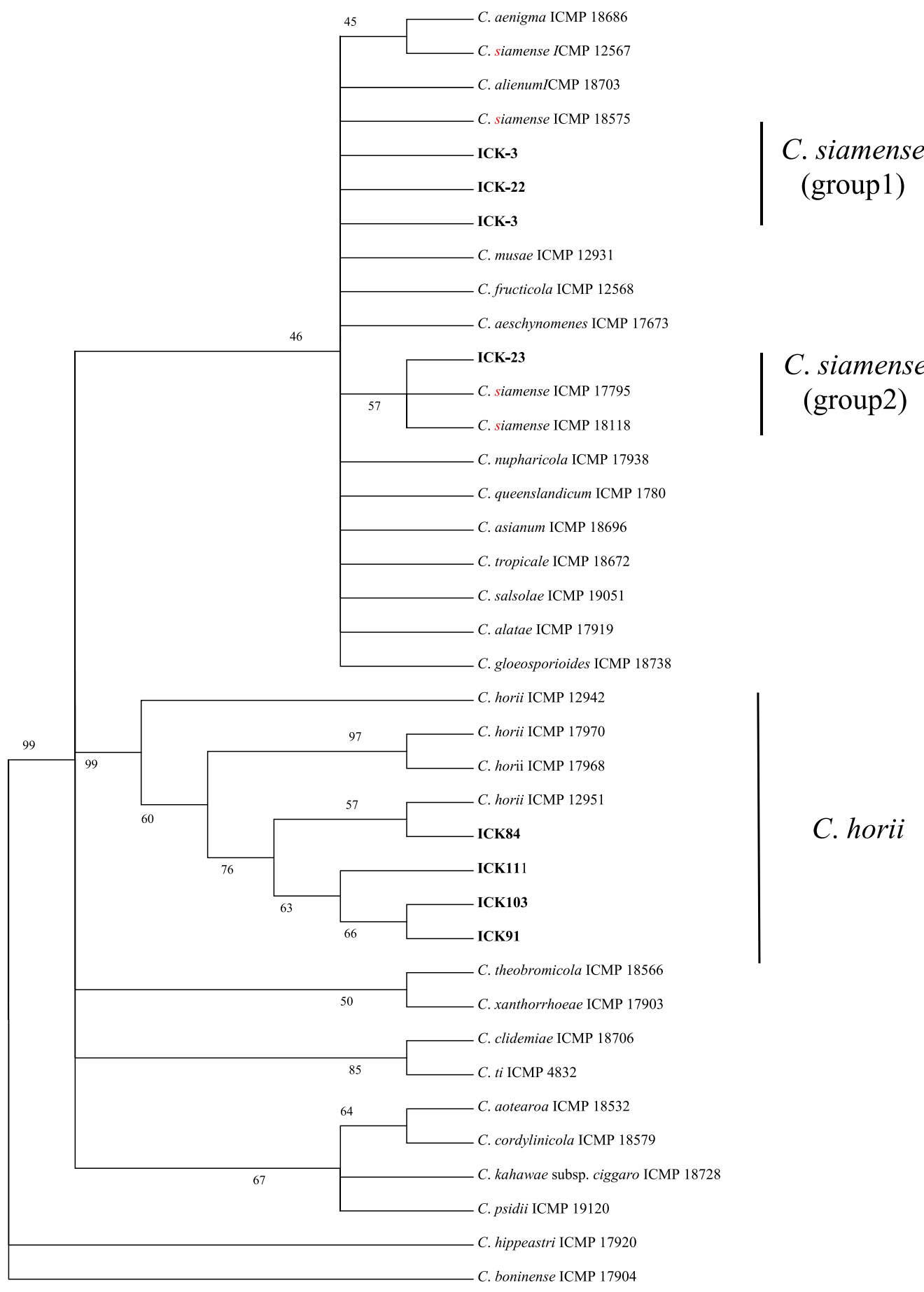

Musae clade

C. siamense

(group2)

C. horii

Fig. 2. Phylogenetic analysis using the maximum-parsimony method to compare the nucleotide sequences of actin, glyceraldehyde-3-phosphate dehydrogenase, and internal transcribed spacer from the present isolates with those of other Colletotrichum spp. in the Colletotrichum gloeosporioides species complex retrieved from GenBank. Numbers above the branches represent bootstrap values. 


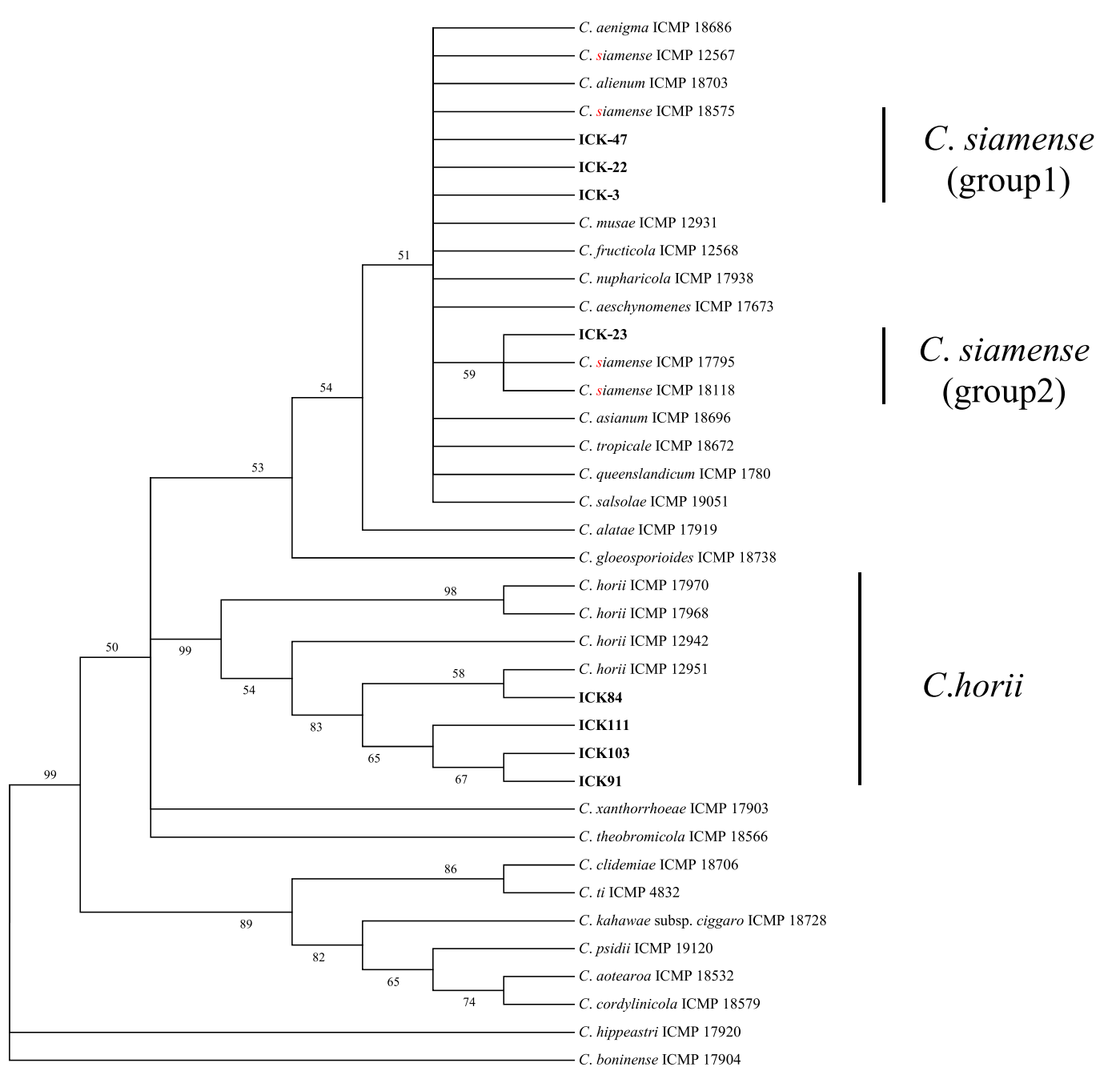

\section{Musae clade}

C. siamense

(group2)

Kahawae clade

Fig. 3. Phylogenetic analysis using the neighbor-joining method to compare the nucleotide sequences of actin, glyceraldehyde-3-phosphate dehydrogenase, and internal transcribed spacer from the present isolates with those of other Colletotrichum spp. in the Colletotrichum gloeosporioides species complex retrieved from GenBank. Numbers above the branches represent bootstrap values.

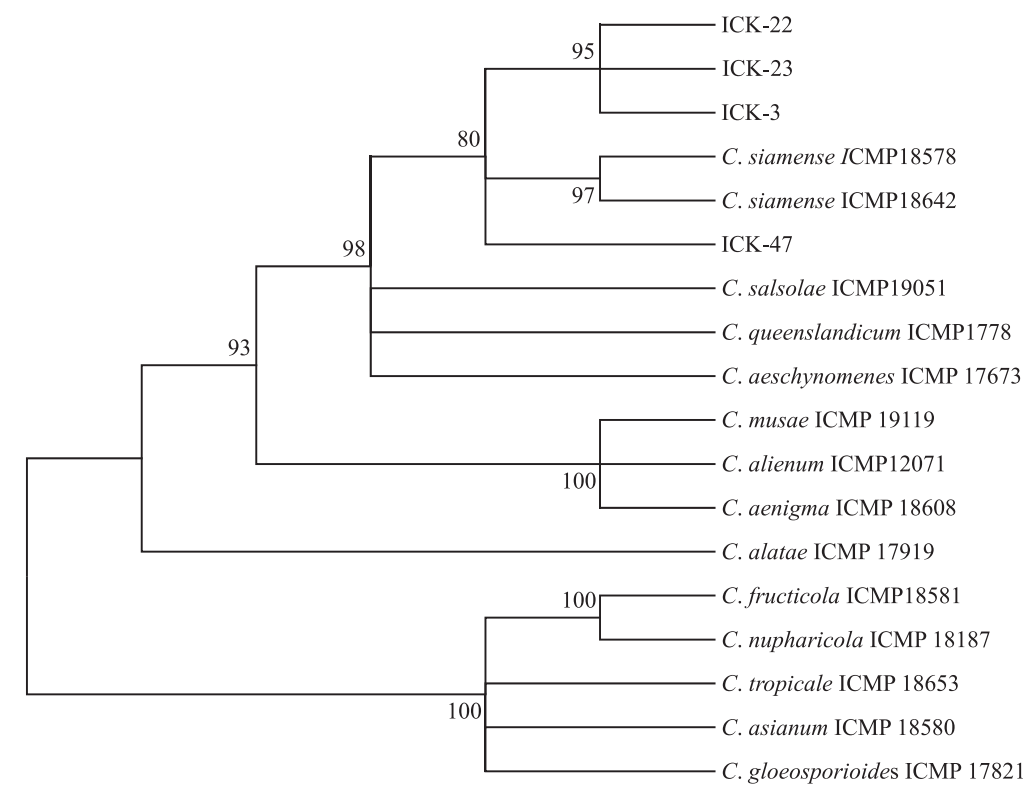

Fig. 4. Phylogenetic analysis using the neighbor-joining method to compare the nucleotide sequences of internal transcribed spacer, actin, glyceraldehyde-3-phosphate dehydrogenase, calmodulin, and Apn2-Mat1-2 intergenic spacer partial mating type from the present Colletotrichum siamense isolates with those of other Colletotrichum spp. within the Musae clade of the $\mathrm{C}$. gloeosporioides species complex retrieved from GenBank. Numbers above the branches represent bootstrap values. 
complex, were isolated and identified from Cheongdo-gun and Sangju, respectively. C. siamense was described in this study as a cause of anthracnose disease of persimmon in South Korea. C. horii was the only species from the C. gloeosporioides species complex previously reported to cause anthracnose in persimmon in South Korea (Kwon and Kim 2011; Kwon et al. 2013).

Originally, $C$. siamense was isolated from coffee berries in Thailand (Prihastuti et al. 2009). C. siamense has also been reported as
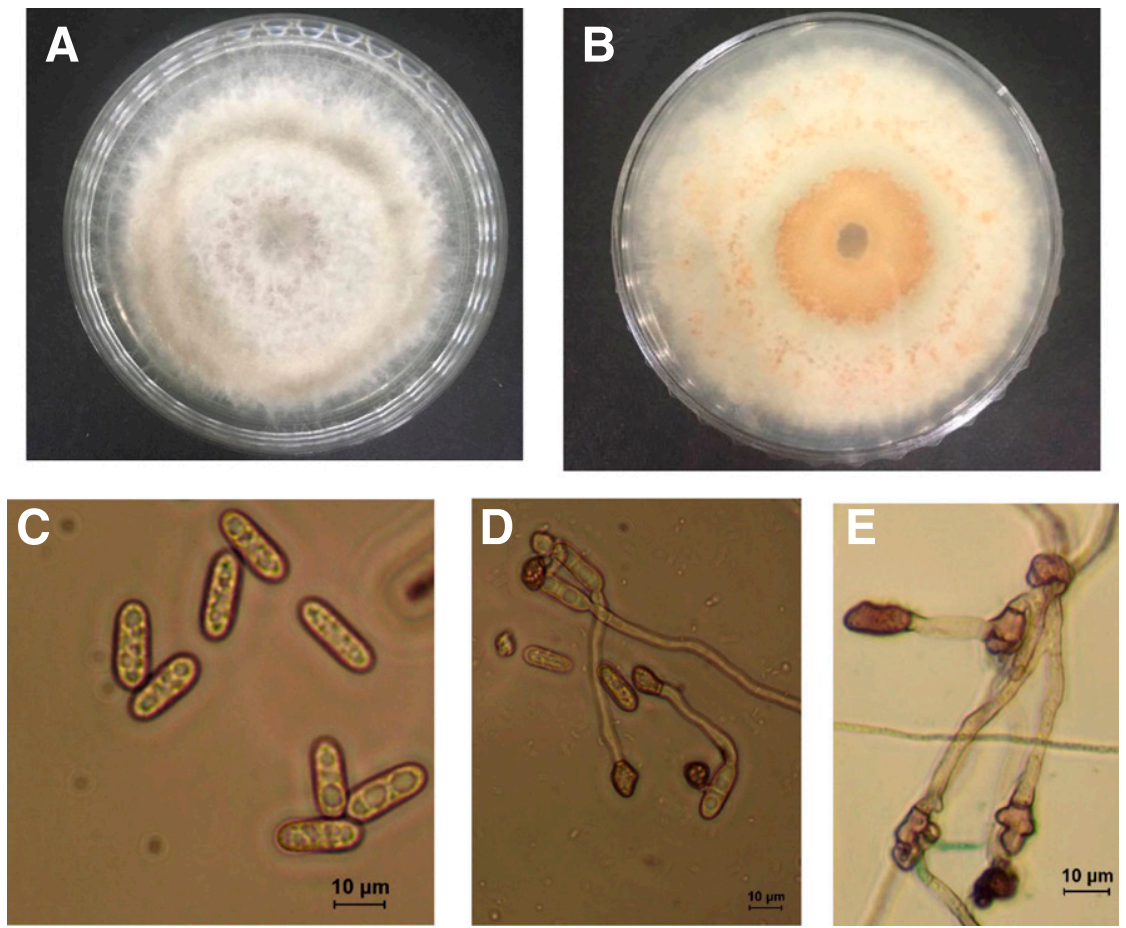

Fig. 5. Culture and morphological characteristics of Colletotrichum siamense isolated from Diospyros kaki. Colony on potato dextrose agar after 7 days of incubation at $25^{\circ} \mathrm{C} \mathrm{A}$, from above; B, from below; C, conidia; D, conidia and appressoria; $E$, appressoria. Scale bars: $C=20 \mu \mathrm{m}$ and $\mathrm{D}=10 \mu \mathrm{m}$.
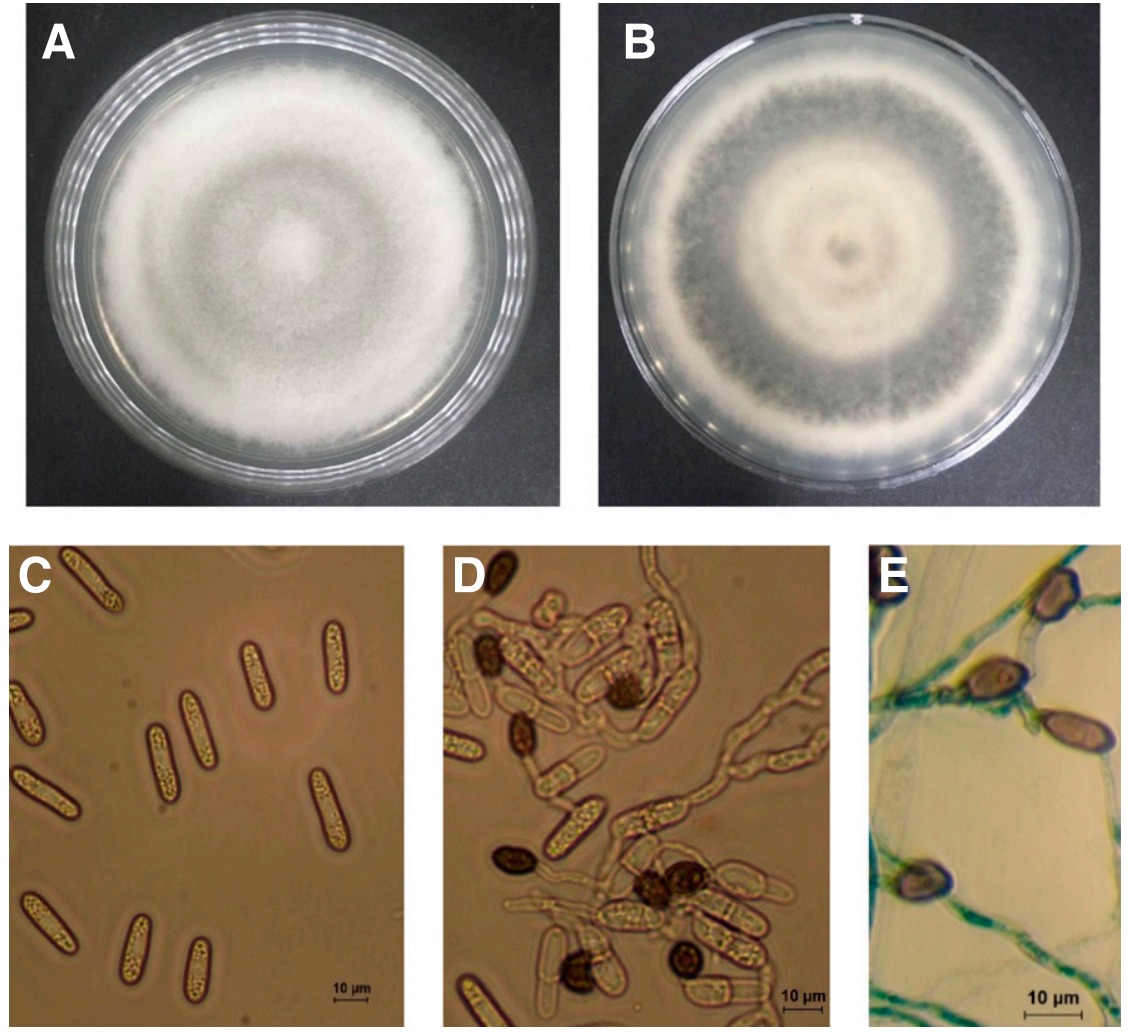

Fig. 6. Culture and morphological characteristics of Colletotrichum horii isolated from Diospyros kaki. Colony on potato dextrose agar after 7 days of incubation at $25^{\circ} \mathrm{C} \mathrm{A}$, from above; B, from below; C, conidia; D, conidia and appressoria; E, appressoria. Scale bars: C $=20 \mu \mathrm{m}$ and D $=10 \mu \mathrm{m}$. 
a disease-causing agent of Persea americana, Pistacia vera, Hymenocallis americana, Dioscorea rotundata, Carica papaya, Capsicum annuum, Vitis vinifera, Fragaria $\times$ ananassa, Malus domestica, and Jasminium sambac (Weir et al. 2012). Colletotrichum horii has been reported to cause minor signs of disease on inoculated fruit of Capsicum annuum, Musa acuminata, and Cucurbita pepo but it has not been shown to be responsible for disease in these hosts in the field (Weir et al. 2012). Colletotrichum horii is the species most frequently reported as a cause of persimmon anthracnose in the world (Jeon et al. 2017; Kwon and Kim 2011; Kwon et al. 2013; May De Mio et. al. 2015; Weir and Johnston 2010; Xie et al. 2010; Zhang 2008).

$C$. siamense and $C$. horii have been isolated from astringent persimmon (Diospyros kaki) in South Korea, although C. horii was previously isolated from sweet persimmon (Kwon and Kim 2011; Kwon et al. 2013). Phylogenetic analysis based on multigene sequences clearly differentiated between the two species. A phylogeny based on ITS, ACT, and GAPDH nucleotide sequences revealed that $C$. horii clustered in a distinct phylogenetic clade from other species of the $C$. gloeosporioides complex. ITS is considered to be the most informative gene marker to differentiate $C$. horii from all other Colletotrichum spp. (Weir et al. 2012). Morphological features of C. horii isolates in the present study were almost the same as those of $C$. horii isolates described by Weir and Johnston (2010) (Table 5).

ITS, ACT, and GAPDH nucleotide sequences from $C$. siamense were variable but the phylogenetic tree constructed from these genes revealed that all isolates clustered with $C$. siamense reference isolates, and that ICMP 12567, ICMP 17795, ICMP 18118, and ICMP 18575 clustered in the Musae clade of the $C$. gloeosporioides species complex. The combined gene analysis of ITS, ACT, and GAPDH did

Table 4. Lesion diameter and disease incidence of Colletotrichum spp. inoculated by wounding method in persimmon fruit $^{z}$

\begin{tabular}{lcc}
\hline Species name & $\begin{array}{c}\text { Lesion diameter on } \\
\text { persimmon } \\
\text { fruit }(\mathbf{m m} \pm \mathbf{S E})\end{array}$ & $\begin{array}{c}\text { Disease incidence } \\
\mathbf{( \% )}\end{array}$ \\
\hline $\begin{array}{l}\text { Colletotrichum siamense } \\
\text { ICK-47 }\end{array}$ & $20.15 \pm 1.40 \mathrm{a}$ & 100 \\
C. siamense ICK-23 & $19.44 \pm 0.67 \mathrm{a}$ & 100 \\
C. horii ICK-103 & $7.64 \pm 0.85 \mathrm{~b}$ & 100 \\
C. horii ICK-111 & $8.15 \pm 0.75 \mathrm{~b}$ & 100 \\
\hline
\end{tabular}

${ }^{\mathrm{z}} \mathrm{SE}=$ standard error. Treatment means followed by the same letter are not significantly different. not reliably separate $C$. siamense from the other Colletotrichum spp. in the Musae clade of the $C$. gloeosporioides complex. Identification of C. siamense was then confirmed by a combined ITS, ACT, GAPDH, CAL, and ApMat gene analysis, which best distinguished C. siamense species (Fig. 4). CAL is the most informative gene to differentiate $C$. siamense isolates from all other species, whereas the ApMat gene improves systematics of the $C$. gloeosporioides species complex (Silva et al. 2012; Weir et al. 2012).

The shape of the conidia and appressoria of the present isolates matched those of $C$. siamense described by Prihastuti et al. (2009) but they differed in size (Table 5). The conidia and appressoria of the present isolates were bigger than those of the reference $C$. siamense isolate. Morphological features may change in response to environment, growth media, and type of host (Hu et al. 2015; Hyde et al. 2009; Weir et al. 2012).

The identified $C$. siamense isolates and $C$. horii isolates showed distinct colony morphologies, with small variations in colony growth rates, conidia sizes and shape, and appressoria sizes and shape (Table 5). These variations were consistent with those of other C. siamense and C. horii (Weir et al. 2012).

The morphological characteristics of the present $C$. siamense and $C$. horii isolates overlapped with those of other species in the C. gloeosporioides complex (Weir et al. 2012). The analysis of the combined ITS, ACT, and GAPDH genes separated the above two taxa and supported the distinction between C. horii and other isolates in the $C$. gloeosporioides complex. An additional combined analysis of ITS, ACT, GAPDH, CAL, and ApMat genes supported the distinction of $C$. siamense from other isolates in the group. Recently, $C$. siamense has been recognized as a new species complex within the $C$. gloeosporioides complex, and this urgently needs phylogenetic reassessment (Doyle et al. 2013; Udayanga et al. 2013). Silva et al. (2012) reported that a new set of primers targeting the Apn2/ MAT locus may be used to determine the phylogenetic relation of $C$. siamense with other members in the $C$. gloeosporioides complex. The problem in determining the placement of the tested $C$. siamense isolates was due to a lack of ApMat sequence data for novel species. These isolates may play a vital role in refining our understanding of the extent of cryptic diversification in Colletotrichum subcomplexes in the future.

All of the tested Colletotrichum isolates showed the same degree of virulence. Both groups of isolates (C. horii and C. siamense) were able to infect wounded persimmon fruit and produce black lesions. These black lesions are the visual sign of anthracnose disease. Though these experiments disregarded the importance of the epidermis as a resistance barrier to initial infection, the results proved that

Table 5. Morphological characteristics of Colletotrichum siamense and C. horii species described in this study and closely related reference species

\begin{tabular}{|c|c|c|c|c|}
\hline Characteristics & $\begin{array}{l}\text { C. siamense (isolates from } \\
\text { Thailand) })^{\mathrm{y}}\end{array}$ & C. siamense (present isolate) & C. horii (present isolate) & C. horii (isolate from Japan) ${ }^{\mathbf{z}}$ \\
\hline Colony & $\begin{array}{l}\text { At first white and becoming pale- } \\
\text { brownish to pinkish, reverse } \\
\text { pale yellowish to pinkish }\end{array}$ & $\begin{array}{l}\text { White to off white, in reverse } \\
\text { creamy yellow, dull yellow } \\
\text { toward the center, yellowish } \\
\text { conidial mass across the colony }\end{array}$ & $\begin{array}{l}\text { White at first, became grayish } \\
\text { over time, cottony, in reverse, } \\
\text { darker concentric zone, margin } \\
\text { of colony regular }\end{array}$ & $\begin{array}{l}\text { Pale gray, cottony, conidia } \\
\text { develop across the whole } \\
\text { colony, in reverse, darker } \\
\text { concentric bands, margin of } \\
\text { colony regular }\end{array}$ \\
\hline \multicolumn{5}{|l|}{ Conidia } \\
\hline Shape & $\begin{array}{l}\text { One-celled, smooth-walled, } \\
\text { guttulate, hyaline, fusiform with } \\
\text { obtuse to slightly rounded ends, } \\
\text { sometimes oblong }\end{array}$ & $\begin{array}{l}\text { Cylindric, straight nonseptate, } \\
\text { fusiform with obtuse ends and } \\
\text { guttulate }\end{array}$ & $\begin{array}{l}\text { Cylindrical, straight, a few } \\
\text { slightly curved, nonseptate, } \\
\text { obtuse at both ends, a few } \\
\text { tapering toward the base }\end{array}$ & $\begin{array}{l}\text { Mostly cylindric, straight, ends } \\
\text { broadly rounded, a few tapering } \\
\text { toward the base }\end{array}$ \\
\hline Size $(\mu \mathrm{m})$ & $\begin{array}{l}7-18.3 \times 3-4.3 \text { (average: } 10.18 \times \\
3.46 \text { ) }\end{array}$ & $\begin{array}{l}12.0-18.6 \times 3.5-6.1 \text { (average: } \\
15 \times 5)\end{array}$ & $\begin{array}{l}14.5-20.8 \times 4.0-5.78 \text { (average: } \\
17 \times 4.5 \text { ) }\end{array}$ & $\begin{array}{l}15-21 \times 4-5.5 \text { (average: } 17.6 \times \\
4.8)\end{array}$ \\
\hline \multicolumn{5}{|c|}{ ( } \\
\hline Shape & $\begin{array}{l}\text { Brown, ovoid, sometimes clavate } \\
\text { and often becoming complex } \\
\text { with age }\end{array}$ & $\begin{array}{l}\text { Brown, varied shapes, irregularly } \\
\text { lobed, becoming complex with } \\
\text { age }\end{array}$ & $\begin{array}{l}\text { Short and cylindrical, light brown } \\
\text { to brown, mostly uniform in } \\
\text { outline, a few irregularly lobed }\end{array}$ & $\begin{array}{l}\text { Short and cylindrical, usually } \\
\text { uniform in outline, a few } \\
\text { irregularly lobed }\end{array}$ \\
\hline Size $(\mu \mathrm{m})$ & $4.7-8.3 \times 3.5-5(6.67 \times 4.13)$ & $\begin{array}{l}11.4-19.1 \times 5.2-9.1 \text { (average: } \\
14.2 \times 7.3)\end{array}$ & $\begin{array}{l}9.5-13.8 \times 5.5-8.4 \text { (average: } \\
11.1 \times 7 \text { ) }\end{array}$ & $9.5-13.5 \times 6-8.5$ \\
\hline
\end{tabular}

y Prihastuti et al. (2009).

${ }^{\mathrm{z}}$ Weir and Johnston (2010). 
these two species of Colletotrichum were causal agents of anthracnose on persimmon. The enzyme cutinase produced by $C$. truncatum is very crucial to break down the structural defense of the host tissue (Auyong et al. 2015). Wounding in host tissue greatly enhance infectability of Colletotrichum spp. to cause disease (Pring et al. 1995).

In conclusion, here, we identified two species in the $C$. gloeosporioides complex that cause persimmon anthracnose in South Korea, based on morphological, molecular, and pathogenesis analyses. The identification of a new Colletotrichum spp. causing persimmon anthracnose reflects the importance of further research on Colletotrichum taxonomy to mitigate the risk to the South Korea persimmon fruit industry.

\section{Literature Cited}

Auyong, A. S. M., Ford, R., and Taylor, P. W. J. 2015. The role of cutinase and its impact on pathogenicity of Colletotrichum truncatum. J. Plant Pathol. Microbiol. 6:259.

Badenes, M., Garcés, A., Romero, C., Romero, M., Clavé, J., Rovira, M., and Llacer, G. 2003. Genetic diversity of introduced and local Spanish persimmon cultivars revealed by RAPD markers. Genet. Resour. Crop Evol. 50:579-585.

Cai, L., Hyde, K. D., Taylor, P. W. J., Weir, B., Waller, J., Abang, M. M., Zhang, J. Z., Yang, Y. L., Phoulivong, S., and Liu, Z. Y. 2009. A polyphasic approach for studying Colletotrichum. Fungal Divers. 39:183-204.

Cannon, P. F., Damm, U., Johnston, P. R., and Weir, B. S. 2012. ColletotrichumCurrent status and future directions. Stud. Mycol. 73:181-213.

Carbone, I., and Kohn, L. M. 1999. A method for designing primer sets for speciation studies in filamentous ascomycetes. Mycologia 91:553-556.

Damm, U., Cannon, P. F., Woudenberg, J. H. C., and Crous, P. W. 2012a. The Colletotrichum acutatum species complex. Stud. Mycol. 73:37-113.

Damm, U., Cannon, P. F., Woudenberg, J. H. C., Johnston, P. R., Weir, B. S., Tan, Y. P., Shivas, R. G., and Crous, P. W. 2012b. The Colletotrichum boninense species complex. Stud. Mycol. 73:1-36.

Dean, R., Van Kan, J. A., Pretorius, Z. A., Hammond-Kosack, K. E., Di Pietro, A., Spanu, P. D., Rudd, J. J., Dickman, M., Kahmann, R., Ellis, J., and Foster, G. D. 2012. The top 10 fungal pathogens in molecular plant pathology. Mol. Plant Pathol. 13:414-430.

Diao, Y.-Z., Zhang, C., Liu, F., Wang, W.-Z., Liu, L., Cai, L., and Liu, X.-L. 2017. Colletotrichum species causing anthracnose disease of chili in China. Persoonia 38:20-37.

Doyle, V. P., Oudemans, P. V., Rehner, S. A., and Litt, A. 2013. Habitat and host indicate lineage identity in Colletotrichum gloeosporioides s.l. from wild and agricultural landscapes in North America. PLoS One 8:e62394.

FAO. 2014. Crop production database FAOSTAT. Online publication. Food and Agriculture Organization of the United Nations(FAO). http://faostat.fao.org/ default.aspx

Hu, M. J., Grabke, A., and Schnabel, G. 2015. Investigation of the Colletotrichum gloeosporioides species complex causing peach anthracnose in South Carolina. Plant Dis. 99:797-805.

Huang, F., Chen, G. Q., Hou, X., Fu, Y. S., Cai, L., Hyde, K. D., and Li, H. Y. 2013. Colletotrichum species associated with cultivated citrus in China. Fungal Divers. 61:61-74.

Hyde, K. D., Cai, L., Mckenzie, E. H. C., Yang, Y. L., Zhang, J. Z., and Prihastuti, H. 2009. Colletotrichum: A catalogue of confusion. Fungal Divers. 39:1-17.

Jeon, J. Y., Hassan, O., Chang, T., Lee, D. W., Shin, J. S., and Oh, N. K. 2017. Anthracnose of Persimmon (Diospyros kaki) Caused by Colletotrichum horii in Sangju, Korea. Plant Dis. 101:1035.
Kwon, J. H., and Kim, J. 2011. First report of fruit black spot of Diospyros kaki caused by Colletotrichum acutatum in Korea. Plant Pathol. J. 27:100.

Kwon, J.-H., Kim, J., Choi, O., Gang, G.-H., Han, S., and Kwak, Y.-S. 2013 Anthracnose caused by Colletotrichum horii on sweet persimmon in Korea: Dissemination of conidia and disease development. J. Phytopathol. 161: 497-502.

Liu, F., Tang, G., Zheng, X., Li, Y., Sun, X., Qi, X., You Zhou, Y., Xu, J., Chen, H., Chang, X., Zhang, S., and Gong, G. 2016. Molecular and phenotypic characterization of Colletotrichum species associated with anthracnose disease in peppers from Sichuan Province, China. Sci. Rep. 6: Article 32761.

Luo, Z., and Wang, R. 2008. Persimmon in China: Domestication and traditional utilizations of genetic resources. Adv. Hortic. Sci. 22:239-243.

May De Mio, L. L., Silva, F. A., Blood, R. Y., and Figueiredo, J. A. G. 2015. Twig blight and defoliation caused by Colletotrichum horii in persimmons in Brazil. Rev. Bras. Frutic. 37:256-260.

Palou, L., Montesinos-Herrero, C., Tarazona, I., Besada, C., and Taberner, V. 2015. Incidence and etiology of postharvest fungal diseases of persimmon (Diospyros kaki Thunb. cv. Rojo Brillante) in Spain. Plant Dis. 99:1416-1425.

Phoulivong, S., Cai, L., Chen, H., McKenzie, E. C., Abdelsalam, K., Chukeatirote, E., and Hyde, K. 2010. Colletotrichum gloeosporioides is not a common pathogen on tropical fruits. Fungal Divers. 44:33-43.

Prihastuti, H., Cai, L., Chen, H., McKenzie, E. H. C., and Hyde, K. D. 2009. Characterisation of Colletotrichum species associated with coffee berries in northern Thailand. Fungal Divers. 39:89-109.

Pring, R. J., Nash, C., Zakaria, M., and Bailey, J. A. 1995. Infection process and host range of Colletotrichum capsici. Physiol. Mol. Plant Pathol. 46:137-152.

Silva, D. N., Talhinhas, P., Várzea, V., Cai, L., Paulo, O. S., and Batista, D. 2012 Application of the Apn2/MAT locus to improve the systematics of the Colletotrichum gloeosporioides complex: An example from coffee (Coffea spp.) hosts. Mycologia 104:396-409.

Tamura, K., Stecher, G., Peterson, D., Filipski, A., and Kumar, S. 2013. MEGA6: Molecular evolutionary genetics analysis version 6.0. Mol. Biol. Evol. 30: 2725-2729.

Templeton, M. D., Rikkerink, E. H., Solon, S. L., and Crowhurst, R. N. 1992. Cloning and molecular characterization of the glyceraldehyde-3-phosphate dehydrogenase-encoding gene and cDNA from the plant pathogenic fungus Glomerella cingulata. Gene 122:225-230.

Udayanga, D., Manamgoda, D. S., Liu, X., Chukeatirote, E., and Hyde, K. D. 2013. What are the common anthracnose pathogens of tropical fruits? Fungal Divers. 61:165-179.

Wang, J., Ai, C. X., Yu, X. M., An, M., Sun, S., and Gao, R. 2016. First report of Colletotrichum karstii causing anthracnose on persimmon leaves in China. Plant Dis. 100:532.

Wang, Y. C., Hao, X. Y., Wang, L., Xiao, B., Wang, X. C., and Yang, Y. J. 2016. Diverse Colletotrichum species cause anthracnose of tea plants (Camellia sinensis (L.) O. Kuntze) in China. Sci. Rep. 6: Article 35287.

Weir, B. S., and Johnston, P. R. 2010. Characterisation and neotypification of Gloeosporium kaki Hori as Colletotrichum horii nom. nov. Mycotaxon 111 209-219.

Weir, B. S., Johnston, P. R., and Damm, U. 2012. The Colletotrichum gloeosporioides species complex. Stud. Mycol. 73:115-180.

White, T. J., Bruns, T., Lee, S. B., and Taylor, J. W. 1990. Amplification and direct sequencing of fungal ribosomal RNA genes for phylogenetics. Pages 315-322 in: PCR Protocols: A Guide to the Methods and Applications. M. A. Innis, D. H Gelfand, J. J. Sninsky, and T. J. White, eds. Academic Press, San Diego, CA.

Williamson, S. M., and Sutton, T. B. 2010. First report of anthracnose caused by Colletotrichum acutatum on persimmon fruit in the United States. Plant Dis. 94:634.

Xie, L., Zhang, J., Cai, L., and Hyde, K. D. 2010. Biology of Colletotrichum horit, the causal agent of persimmon anthracnose. Mycology 1:242-253.

Zhang, J.-Z. 2008. Anthracnose of persimmon caused by Colletotrichum gloeosporioides in China. Asian Australas. J. Plant Sci. Biotechnol. 2:50-54. 